\title{
INCREASED ARTERIAL DISTENSIBILITY AND RENOVASCULAR HYPERTENSION IN GOLDENHAR SYNDROME
}

\author{
Luciano F. Drager, Hélio Bernardes Silva, and Luiz A. Bortolotto
}

DRAGER LF et al. Increased arterial distensibility and renovascular hypertension in goldenhar syndrome. CLINICS 60(2):173-176, 2005.

This is a report of the successful angioplastic treatment of an association of renovascular hypertension with renal artery stenosis and the Goldenhar syndrome (a variant of oculoauriculovertebral dysplasia). For the first time to date, this association, which occurred in a 13-year-old girl, is reported. Additionally, increased arterial distensibility in spite of arterial hypertension was detected by noninvasive methods. The similarity of this finding and in those for other genetic diseases, suggests that the vascular lesions could be linked to the Goldenhar syndrome.

KEYWORDS: Goldenhar syndrome. Renovascular hypertension. Arterial distensibility.

Goldenhar syndrome, a variant of oculoauriculovertebral dysplasia, includes a wide spectrum of anomalies characterized by a combination of hemifacial microsomia and other findings such as epibulbar dermoids or lipodermoids, microtia, auricular appendages, mandibular hypoplasia, vertebral anomalies, ${ }^{1}$ and malformations in several organs, including the heart. ${ }^{2}$ Embryologically, the oculoauriculovertebral defect has been called an anomaly of the first branchial arch, ${ }^{2}$ but this alteration does not explain anomalies in the brain, heart, kidneys, or spine. ${ }^{3}$

Despite numerous case reports, the condition is still poorly understood. In the largest study describing phenotypic characteristics of 294 individuals with oculoauriculovertebral dysplasia and variants, $5 \%$ had cardiovascular abnormalities, including cardiomegaly, cardiac vessel anomalies, ventricular hypertrophy, atrial and ventricular septal defects, tetralogy of Fallot, arterial anomalies, aortic stenosis, and pulmonary artery anomalies. ${ }^{4}$

An unusual association of this syndrome and renovascular hypertension that has not yet been described is re-

From the Hypertension Unit, Heart Institute, Hospital das Clínicas, Faculty of Medicine, University of São Paulo - São Paulo/SP, Brazil.

E-mail: hipluiz@incor.usp.br

Received for publication on June 08, 2004.

Accepted for publication on November 24, 2004. ported in this paper. Moreover, an analysis of aortic distensibility by pulse wave velocity measurement and carotid distensibility with an echo-tracking device to evaluate possible elastic disturbances of the large arteries associated with this syndrome are performed.

\section{CASE REPORT}

A 13-year-old girl was admitted with a recent diagnosis of stage 2 arterial hypertension according to the VII Joint National Comitee. ${ }^{5}$ She had previously been diagnosed with Goldenhar syndrome, characterized by fibroma in left femur, asymmetry of legs, convergent strabismus in the left eye, corneal anomaly, epibulbar dermoids, facial asymmetry (Figure 1), mandibular hypoplasia, low implantation of the left ear, flat plane hemangioma on the left index finger, and vertebral abnormalities (facio-auriculo-vertebral spectrum). In order to treat her hypertension, an antihypertensive therapy with a low sodium diet, captopril $50 \mathrm{mg} /$ day, and propranolol $40 \mathrm{mg} /$ day was introduced.

The patient was born at term, and delivery was through cesarean section without complications. Pregnancy was uneventful. Her chromosome constitution was 46, XX. The parents are not consanguineous, and there are no similar cases in the family. When she was 2 years old, persistent 
truncus arteriosus was detected and was surgically repaired.

Routine laboratory tests and echocardiography were normal. The electrocardiogram showed signs of left ventricular overload. Kidney ultrasonography showed a small right kidney (74 $\mathrm{mm})$ and a normal left kidney (100 mm). Renal scintigraphy showed a decreased perfusion in the right kidney (20\%) compared to the left kidney. A radioimmunoassay for the measurement of plasmatic renin activity detected a high level - $18 \mathrm{ng} / \mathrm{mL} / \mathrm{h}$ (normal range, 01 to $2.3 \mathrm{ng} / \mathrm{mL} / \mathrm{h})$.

The digital arteriography showed a tightly stenotic lesion $(80 \%)$ in the proximal right renal artery (Figure 2$)$. The patient underwent an aorto-right renal artery bypass without complications. Intraoperative anatomical findings of renal artery were compatible with the diagnosis of fibrodysplasia of the renal artery.

In order to evaluate arterial distensibility, a pulse wave velocity analysis by Complior ${ }^{\mathrm{O}}$ was performed and revealed a value of $5.4 \mathrm{~m} / \mathrm{s}$ (lower than mean values obtained from 10 healthy age-matched women $-7.2 \pm 1.2 \mathrm{~m} / \mathrm{s}$ ). A high definition ultrasound with an echo-tracking device (Wall Track System ${ }^{\text {) }}$ ) of carotid artery was also performed and revealed a distensibility of $53.5 \mathrm{kPa}^{-1} 10^{-3}$ (higher than mean values obtained from 10 healthy age-matched women -

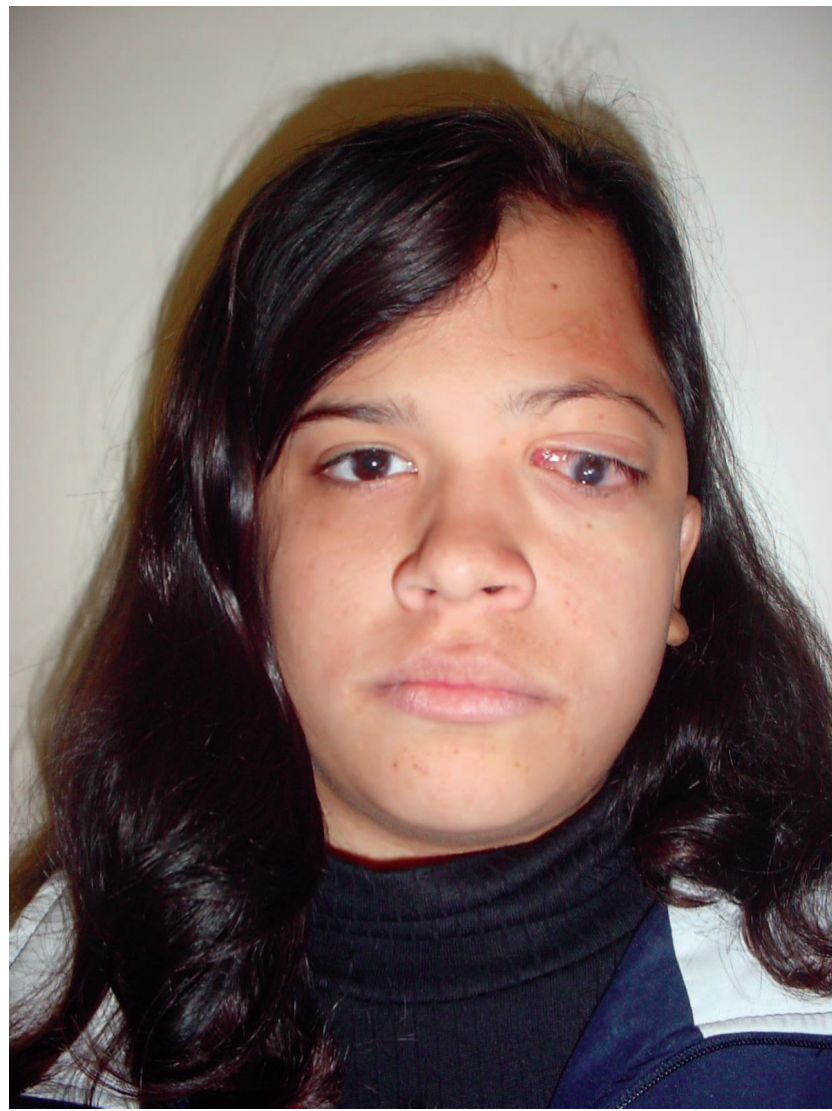

Figure 1 - Reported patient, now aged 18. Patient has given written authorization for the publication of this picture. $\left.20.7 \pm 5 \mathrm{kPa}^{-1} 10^{-3}\right)$, suggesting a high distensibility of the large arteries in this patient (Figure 3 ).

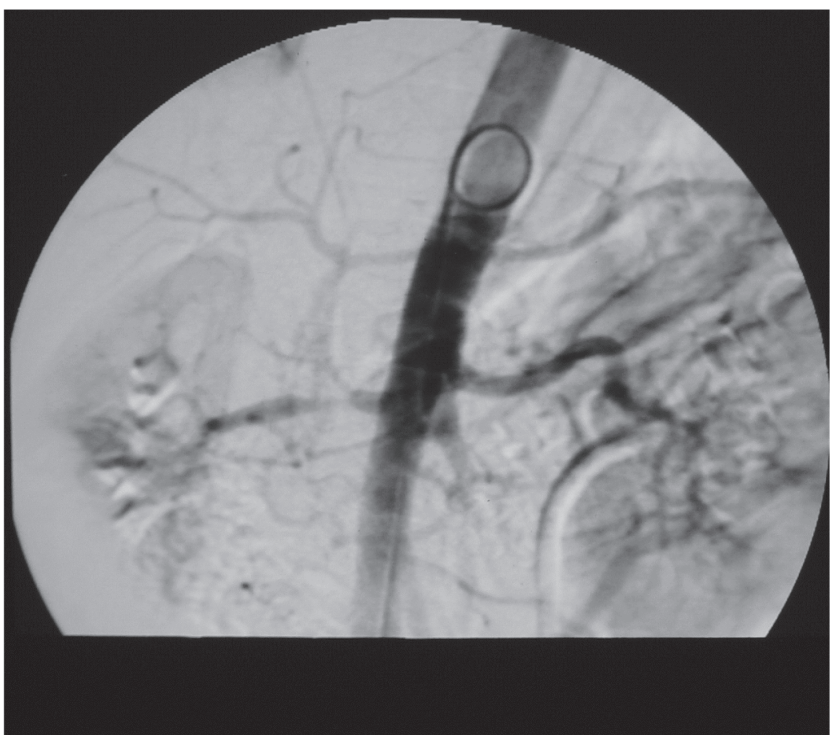

Figure 2 - Renal arteriography showing right renal artery stenosis (arrow).
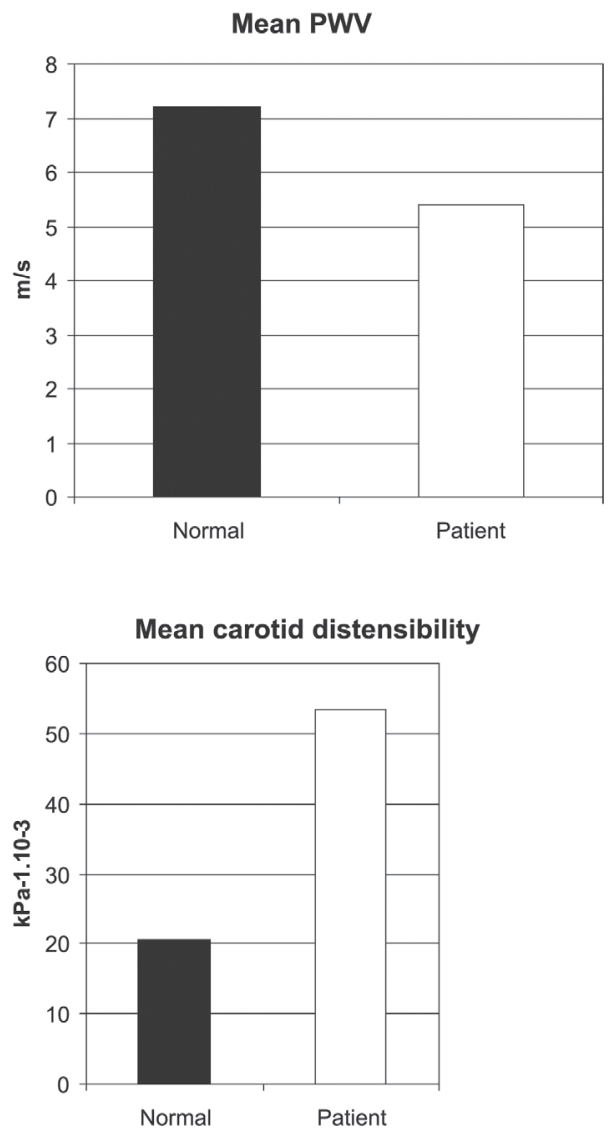

Figure 3 - Vascular data obtained in a group of 10 healthy women aged $14 \pm 3$ years compared to that of the patient with Goldenhar syndrome: mean pulse wave velocity values (Panel A) and mean carotid distensibility values (Panel B). PWV: Healthy women $7.2 \pm 1.2 \mathrm{~m} / \mathrm{s}$; patient $5.4 \mathrm{~m} / \mathrm{s}$; Carotid distensibility: Healthy women $20.7 \pm 5 \mathrm{~m} / \mathrm{s}$; patient $53.5 \mathrm{~m} / \mathrm{s}$. 
After four years, she remained asymptomatic, with her blood pressure under control with the use of enalapril $5 \mathrm{mg} /$ day and a preserved renal function. Renal scintigraphy showed an improvement of the right kidney flow.

\section{DISCUSSION}

For the first time to date, an association of renovascular hypertension with renal artery stenosis and Goldenhar syndrome is reported. Additionally, an increased arterial distensibility despite the arterial hypertension has been detected by noninvasive methods when what is usually observed is a reduced distensibility in large elastic arteries but an unchanged distensibility of middle size arteries. ${ }^{6}$

In Goldenhar syndrome, the main phenotypic findings include microtia, mandibular hypoplasia, vertebral anomalies, and epibulbar dermoids or lipodermoids. However, many patients have been reported presenting with associated multisystem complex anomalies within this disorder including alterations in respiratory, skin, skeletal, genitourinary, gastrointestinal, central nervous, muscular, and endocrine systems. ${ }^{4}$ Cardiovascular abnormalities were described only in $5 \%$ of the cases. However, the real frequency of cardiovascular malformations of Goldenhar syndrome is unknown, since great variability is reported in the literature (5\% to $58 \%) .{ }^{7}$ The main reason for this variation are selection bias and differences in diagnostic criteria adopted.

Previous reports essentially described congenital heart diseases, and tetralogy of Fallot is the most common cardiac malformation encountered, occurring in 6 of 13 cases of Goldenhar syndrome. ${ }^{8}$ Other cardiovascular malformations reported include coarctation of the aorta, patent ductus arteriosus, transposition of the great arteries, dextrocardia with situs solitus, atrial and ventricular septal defects, anomalous origin of the coronary arteries, right-sided descending aorta, anomalous inferior and superior venae cavae, and arrhythmic disturbances, such as the WolffParkinson-White syndrome. The reported patient had a surgically corrected patent ductus arteriosus. However, none of the previous reports mentioned arterial hypertension or renal artery stenosis in patients with Goldenhar syndrome.

Another unusual feature of this case is the increased distensibility of aorta and carotid artery. This finding is similar to those described in other genetic disorders, including Williams syndrome, ${ }^{9}$ Ehlers-Danlos syndrome, ${ }^{10}$ and Fabry disease. In Williams syndrome, using the same echo-tracking device we used, the authors demonstrated a higher carotid distensibility related to the disruption of the elastin gene, ${ }^{9}$ while in patients with Ehlers-Danlos syndrome, a lower pulse wave velocity was observed, as noted in the reported patient, due to a deficiency of type II collagen occurring with this syndrome. ${ }^{10}$

A variety of diseases can lead to renovascular hypertension in childhood. ${ }^{11}$ Fibrodysplasia is the most frequent cause, but thromboembolism, inflammatory stenoses, atherosclerosis, tumors, retroperitoneal fibrosis, and genetic disorders are other possible causes. The most common genetically determined disorder is neurofibromatosis, an autosomal-dominant congenital dysplasia of ectodermal and mesodermal tissues characterized by café-au-lait spots, cutaneous fibromas, neurofibromas and vascular lesions. ${ }^{12}$ In adult patients with neurofibromatosis, the etiology of hypertension is commonly related to concomitant pheochromocytoma, while in pediatric patients it is usually related to renal artery stenosis. ${ }^{13}$ Unlike fibromuscular dysplasia, neurofibromatosis often affects the intrarenal arteries and arterioles in the form of stenosis or bilateral saccular aneurysms. ${ }^{14}$ The vascular lesions in neurofibromatosis include pure intimal lesions; advanced intimal lesions and medial changes; nodular aneurysmal lesions with loss of media elements; periarterial nodular abnormalities; and epithelioid lesions with marked cellular proliferation. In all of these forms, proliferation of spindle cells occurs within arterial walls and may be responsible for the associated internal elastic membrane disruption, degeneration, and protrusion into the media. ${ }^{14}$

Another possibility to consider in differential diagnosis is Williams syndrome, also known as idiopathic hypercalcemia of infancy or the supravalvar aortic stenosis complex. This syndrome is characterized by hypercalcemia in infancy; short stature; "elfin facies"; mental retardation; and stenosis of the aorta, pulmonary, and peripheral systemic arteries. ${ }^{15}$ Like other genetically based disorders, such as the Klippel-Trenaunay-Weber syndrome (cutaneous capillary malformation, abnormal development of the deep and superficial veins, limb asymmetry, and mixed vascular malformations), the renal lesions in these patients appear to be in the category of fibromuscular dysplasia.

Given the knowledge of this disorder and the fact that renal artery stenosis due to fibrodysplasia is usually observed in young women, it is impossible to determine whether renal artery stenosis and Goldenhar syndrome are truly related or just coincidentally occur. However, the similarity of the anatomical findings and the increased arterial distensibility observed in the reported patient and in other genetic diseases suggests that vascular lesions could be linked to the Goldenhar syndrome. Noninvasive studies of functional properties of the large arteries and genetic studies in patients with Goldenhar syndrome should be done to elucidate this question. 
DRAGER LF e col. Aumento de distensibilidade arterial e hipertensão renovascular na Sindrome de Goldenhar. CLINICS 60(2):173-176, 2005.

Relatamos a associação de hipertensão renovascular por estenose de artéria renal e a Sindrome de Goldenhar (variante da displasia oculoauriculovertebral) em uma paciente do sexo feminino de 13 anos de idade. Este é o primeiro relato de tratamento por angioplastia. Além disso, detectamos por métodos não invasivos um aumento da distensibilidade arterial, a despeito da hipertensão arterial. A similaridade destes achados com outras doenças genéticas sugere que as alterações vasculares presentes podem estar relacionadas à Síndrome de Goldenhar.

UNITERMOS: Síndrome de Goldenhar. Hipertensão renovascular. Distensibilidade Arterial.

\section{REFERENCES}

1. Gorlin RJ, Jue KL, Jacobsen U, Goldschmidt E. Oculoauriculovertebral dysplasia. J Pediatr 1963;63:991-9.

2. van Bever Y, van den Ende JJ, Richieri-Costa A. Oculo-auriculovertebral complex and uncommon associated anomalies: Report on 8 unrelated Brazilian patients. Am J Med Genet 1992;44:68390 .

3. Sugar HS. The oculoauriculovertebral dysplasia syndrome of Goldenhar. Am J Ophtalmol 1966;62:678-82.

4. Rollnick BR, Kaye CI, Nagatoshi K, Hauck W, Martin AO. Oculoauriculovertebral dysplasia and variants: Phenotypic characteristics of 294 patients. Am J Med Genet 1993;26:36175 .

5. Chobanian AV, Bakris GL, Black HR, Cushman WC, Green LA, Izzo JL Jr, et al. The seventh report of the Joint National Committee on prevention, detection, evaluation, and treatment of high blood pressure. JAMA 2003;289:2560-72.

6. Mancia G, Giannattasio C. Arterial distensibility and pulse pressure. Measurements and clinical significance in hypertension. Clin Exp Hypertens 1999;21(5-6):615-33.

7. Kumar A, Friedman JM, Taylor GP, Patterson MW. Pattern of cardiac malformation in oculoauriculovertebral spectrum. Am J Med Genet 1993;46(4):423-6.

8. Greenwood RD et al. Cardiovascular malformations in oculoauriculovertebral dysplasia (Goldenhar syndrome). J Pediatr $1974 ; 85: 816-8$.
9. Francois B, De Paepe A, Matton MT, Clement D. Pulse wave velocity recordings in a family with ecchymotic Ehlers-Danlos syndrome. Int Angiol 1986;5(1):1-5.

10. Lacolley P et al. Disruption of the elastin gene in adult Williams syndrome is accompanied by a paradoxical reduction in arterial stiffness. Clin Sci (Lond) 2002;103(1):21-9.

11. Ingelfinger JR. Renovascular disease in children. Kidney Int $1993 ; 43(2): 493-505$

12. Tilford DL, Kelsch RC. Renal artery stenosis in childhood neurofibromatosis. Am J Dis Child 1973;126(5):665-8.

13. Pollard SG, Hornick P, Macfarlane R, Calne RY. Renovascular hypertension in neurofibromatosis. Postgrad Med J 1989;65:31-3.

14. Nakhoul F, Green J, Angel A, Ofer A, Ben-Izhak O, Lewin M. Renovascular hypertension associated with neurofibromatosis: two cases and review of the literature. Clin Nephrol 2001;55(4):322-6.

15. Jones KL. Williams syndrome: an historical perspective of its evolution, natural history, and etiology. Am J Med Genet Suppl 1990;6:89-96. 